\title{
Perancangan Sistem Kontrol Otomatis Turbin Angin Yaw Direction
}

\author{
Ajat Sudrajat ${ }^{1}$, Fitria Hidayanti ${ }^{1}$, V. Vekky R. Repi ${ }^{1}$, Derrian Widjayahakim ${ }^{1}$ \\ ${ }^{1}$ Program Studi Teknik Fisika, Universitas Nasional, Pasar Minggu, Jakarta 12520 \\ *Korespondensi penulis: ajatsudrajatr2@yahoo.com
}

(Received 30-10-2020, Revised: 17-11-2020, Accepted: 24-11-2020)

\begin{abstract}
Abstrak. Desain turbin angin adalah proses menentukan bentuk dan spesifikasi turbin angin untuk mengekstraksi energi dari angin. Instalasi turbin angin terdiri dari sistem yang diperlukan untuk menangkap energi angin, mengarahkan turbin ke arah angin, mengubah putaran mekanis menjadi tenaga listrik, dan sistem lain untuk memulai, menghentikan, dan mengontrol turbin. Perancangan turbin angin pada penelitian ini, adalah turbin angin yang akan menerima energi angin dari arah yaw (Yaw-direction). Gerakan menentukan arah dari terbin angin ini dibantu oleh perangkat lunak LabView dengan menggunakn kontroler arduino sebagai pengendali arah gerakannya. Perancangan sistem kontrol pergerakan sumbu yaw dari turbin angin dengan bantuan perangkat lunak LabView dan arduino untuk mengendalikan motor yang akan memutar roda gigi yang dihubungkan dengan plat. Pergerakan meningkatkan efisiensi dari turbin angin dalam menerima angin yang datang. Hasil pengaturan sistem turbin angin dilakukan pada gerakan motor pada arah yaw, dan data putaran potensiometer terhadap tegangan listrik yang diberikan sebagai inputnya.
\end{abstract}

Kata kunci : sistem kontrol, turbin angin, yaw-direction, horizontal axis wind turbine.

\section{PENDAHULUAN}

Indonesia memiliki banyak wilayah dengan potensi sumber energi angin yang besar. Berdasarkan data dari Kementerian Energi Dan Sumber Daya Mineral (ESDM) pada tahun 2018, tercatat potensi energi angin di Indonesia sebagai berikut: Sukabumi (170 MW), Garut (150 MW), Lebak dan Pandeglang (masing-masing $150 \mathrm{MW}$ ), serta Lombok (100 MW) [1]. Indonesia juga merupakan salah satu negara yang persebaran elektrifikasinya belum merata [2], seperti pada wilayah Nusa Tenggara Timur (NTT), menurut kementrian ESDM, rasio elektrifikasi pada tahun 2018 di wilayah NTT hanya 62.07\%. Selain itu, sumber energi listrik dominan yang digunakan saat ini adalah energi yang berasal dari fosil. Sayangnya ratio penggunaan energi fosil sebagai sumber energi utama di Indonesia sangat dominan yaitu sebesar 58\% dari total energi keseluruhan [2]. Hal ini mempersulit di daerah perbatasan karena untuk mendapatkan energi melalui energi fosil itu membutuhkan biaya logistik yang cukup mahal. Oleh karena itu, pengembangan penggunaan energi melalui energi terbarukan sangatlah penting, agar dapat menjangkau daerah perbatasan dengan lebih mudah. Selain itu perserikatan bangsa-bangsa (PBB) juga membatasi penggunaan bahan bakar energi fosil dalam rangka untuk mengurangi perusakan lingkungan yang disebabkan oleh pemanfaatan energi fosil. Hal ini semakin menguatkan bahwa Indonesia harus semakin berbenah dalam rangka meningkatkan potensi energi listrik dari sumber energi yang terbarukan dan ramah lingkungan. Salah satunya adalah energi angin, di mana merupakan energi terbarukan yang mudah di konversi menjadi energi listrik dan memiliki potensi yang besar.

Peningkatan efisiensi turbin angin masih terus di kembangkan hingga saat ini. Terdapat berbagai cara untuk meningkatkan efisiensi dari turbin angin, yaitu optimasi airfoil, optimasi bentuk blade, dan penambahan sistem kontrol [3]. Untuk mendapatkan energi angin yang optimal, diperlukan perancangan turbin angin yang memiliki efisiensi yang tinggi. Namun, di karenakan pola karakteristik arah angin yang terdapat di Indonesia bersifat acak, menyebabkan pengurangan efisiensi turbin angin konvensional di mana 
hanya bisa mengekstrak energi dari angin satu arah saja. Oleh karena itu, diperlukan perancangan (supporting system) yang mampu mengarahkan rotor turbin angin agar selalu tegak lurus dengan arah angin, dikarenakan angin yang dapat memutar blade adalah angin yang tegak lurus dengan rotor. Disinilah peran penting dari sistem kontrol arah yaw dan pitch pada turbin anginSistem sistem kontrol arah yaw dan pitch mengacu kepada rotasi dari keseluruhan turbin angin dalam sumbu horizontal. Kegunaan dari sistem kontrol arah yaw adalah untuk memastikan rotor turbin berada dalam posisi tegak lurus terhadap arah angin, karena arah angin yang datang tidak selalu dari satu sisi melainkan dari segala sisi dan sulit ditebak $[4,5]$. Dengan begitu daya yang dihasilkan turbin angin dapat lebih dimaksimalkan.

Penambahan sistem kontrol yang dilakukan dengan mengimplementasikan sistem kontrol pada sumbu yaw dari turbin angin merupakan salah satu upaya yang dapat dilakukan. Sistem kontrol sumbu yaw merupakan sistem orientasi yang diperlukan oleh turbin angin untuk menjaga agar poros rotor dapat menghadap ke arah angin datang. Sistem kontrol yaw pada umumnya dikontrol dengan menggunakan sistem otomatis dan bergerak sesuai arah angin datang. Menurut riset yang dilakukan oleh peneliti di negara Cina, diketahui bahwa kemiringan turbin angin terhadap arah angin hingga 30 derajat dapat menyebabkan loss pada kecepatan rotor sebesar $12.92 \%$ hingga $13.30 \%$, hal ini membuktikan bahwa sistem kontrol sumbu yaw perlu diimplementasikan agar rugi-rugi kecepatan rotor dapat diminimalisir dan meningkatkan efisiensi dari turbin angin [6].

Berdasarkan informasi diatas, pentingnya sistem kontrol yaw dibanding dengan pengembangan lain dapat dilihat dari perbedaan 4 buah mode sistem pengendalian yang ada. Secara umum terdapat empat buah mode sistem pengendalian turbin angin yang digunakan, yaitu fixed speed and fixed pitch (FSFP), fixed speed and variable pitch (FSVP), variable speed and fixed pitch (VSFP), variable speed and variable pitch (VSVP). Dimana FSFP hanya dapat menerima satu arah angin dan mode VSVP dapat menerima angin dari segala arah dikarenakan adanya sistem kontrol yaw, inilah mengapa sistem kontrol penting untuk dikembangkan dikarenakan pada arah angin yang tidak bisa ditentukan mode VSVP lebih memberikan performa serta efisiensi konversi daya yang lebih tinggi dari mode lainnya [7].

Artikel ini berfokus pada perancangan sistem kontrol smart system yaw-direction pada turbin angin yang dapat digunakan sebagai media pembelajaran untuk perkembangan turbin angin di Indonesia. Perancangan terdiri dari sebuah alat bantu berupa miniatur turbin angin yang dilengkapi dengan Graphical User Interface (GUI) yang dapat dikontrolkan pengguna.

\section{TINJAUAN LITERATUR}

Turbin angin pertama kali digunakan untuk menghasilkan listrik pada tahun 1887 oleh James Blyth. Blyth membangun turbin angin setinggi 10 meter untuk menjadi sumber listrik penerangan pada pondok miliknya [8]. Penemuan signifikan selanjutnya adalah ditemukannya kedua jenis turbin angin yang digunakan hingga saat ini yaitu vertical axis wind turbine (VAWT), dan horizontal axis wind turbine (HAWT) [9]. VAWT pertama kali ditemukan oleh peneliti bernama Georges Jean Marie Darrieus pada tahun 1931 dan HAWT ditemukan pada tahun 1931. Kemudian penelitian mengenai turbin angin kembali dilakukan oleh NASA pada tahun 1975 yang melakukan riset dalam banyak bidang seperti aerodinamis, struktur, akustik, dan juga sistem kontrol [10].

Setelah itu, turbin angin secara esensial beroperasi pada empat buah mode berbeda, fixed speed, variable speed pada generator, serta fixed pitch, variavle pitch pada sistem pitch. Dari jabaran diatas dapat ditentukan empat buah mode turbin angin yaitu fixed speed and fixed pitch (FSFP), fixed speed and variable pitch (FSVP), variable speed and fixed pitch (VSFP), variable speed and variable pitch (VSVP) [11]. Keempat sistem ini memiliki perbedaan yang dapat dilihat pada tabel 1 . 
Kontrol turbin angin di Indonesia merupakan desain sistem kontrol pitch angle wind turbine horizontal axis menggunakan algoritma firefly [12]. Penggunaan metode firefly bertujuan untuk mengoptimasi parameter kontrol PID. Dengan menggunakan PID didapatkan desain control pitch angle wind turbine pada beberapa set point, yaitu 10.20 dan 40. Hasil respon kecepatan turbin angin yang baik dengan respon yang sangat cepat sesuai dengan set point yang diinginkan. Overshoot untuk masing-masing respon 12.93 untuk set point 10, 22,75 untuk set point 20, dan 45.39 untuk set point 40 . Parameter $k_{\mathrm{p}}=$ $0.5009, k_{\mathrm{i}}=3.4890$, dan $k_{\mathrm{d}}=0.0999$ untuk set point $10, k_{\mathrm{p}}=1.4129, k_{\mathrm{i}}=4.7265$, dan $k_{\mathrm{d}}=$ 0.1000 untuk set point 20 , dan $k_{\mathrm{p}}=1.4836, k_{\mathrm{i}}=4.9901$, dan $k_{\mathrm{d}}=0.0999$ untuk set point 40 .

TABEL 1. Daftar perbedaan mode turbin angin [7].

\begin{tabular}{l|l}
\hline Mode Turbin Angin & \multicolumn{1}{c}{ Penjelasan } \\
\hline FSFP & $\begin{array}{l}\text { Turbin angin dengan mode ini hanya bisa beroperasi secara optimal pada satu } \\
\text { arah dan kecepatan angin dikarenakan kecepatan rotasi tidak dapat dirubah } \\
\text { saat kecepatan atau arah angin berubah, sehingga menghasilkan efisiensi } \\
\text { konversi daya yang cukup rendah dan mudah mengalami stall saat angin diatas } \\
\text { batas ketahanan. }\end{array}$ \\
\hline FSVP & $\begin{array}{l}\text { Mirip seperti turbin FSFP, mode ini juga memberi efisiensi konversi daya yang } \\
\text { rendah, namun lebih dapat mengekstrak energi pada angin yang lebih kencang } \\
\text { dikarenakan kontrol sumbu pitch. }\end{array}$ \\
\hline VSFP & $\begin{array}{l}\text { Mode ini memiliki efisiensi konversi daya yang cukup tinggi dikarenakan } \\
\text { dapat menerima angin dari berbagai arah, namun mudah mengalami stall } \\
\text { dikarenakan batas kecepatan angin yang cukup rendah. }\end{array}$ \\
\hline VSVP & $\begin{array}{l}\text { Mode ini memiliki efisiensi konversi daya yang paling tinggi, karena dapat } \\
\text { menerima angin dari berbagai arah serta berbagai kecepatan namun } \\
\text { dikarenakan lebih banyak sistem kontrol yang diimplementasikan sehingga } \\
\text { menaikan biaya produksi dan biaya pemeliharaannya. }\end{array}$ \\
\hline
\end{tabular}

Pada sistem konrol lain, desain regulator fuzzy untuk sistem kontrol yaw turbin angin dilakukan oleh Stefanos Theodoropoulos dan tiga orang rekannya [13]. Pengujian turbin angin menggunakan sistem kontrol yaw dan tanpa kontrol yaw, hasil yang didapatkan adalah pada setiap kecepatan angin yang diberikan, dengan kecepatan masing-masing sebesar $10 \mathrm{~m} / \mathrm{s}, 15 \mathrm{~m} / \mathrm{s}$, dan $25 \mathrm{~m} / \mathrm{s}$. Terdapat peningkatan keluaran daya yang dihasilkan oleh turbin angin, sebagai contoh pada kecepatan angin $15 \mathrm{~m} / \mathrm{s}$, dan, yaw berada pada sudut 45 derajat, didapatkan peningkatan daya sebesar 4.5 MW dari hasil tanpa penggunaan kontrol. Kontrol PID dianggap optimum dalam mendapatkan overshoot dan hasil yang optimal. Penggunaan sistem kontrol pada turbin angin meningkatkan efisiensi yang dihasilkan oleh turbin angin pada sistem pitch yang menyebabkan turbin dapat menerima angin dengan kecepatan yang lebih tinggi dari biasanya. Penggunaan sistem kontrol yaw meningkatkan daya yang dihasilkan oleh turbin angin secara cukup signifikan. Sehingga penerapan sistem kontrol, terutama sistem yaw yang lebih baik akan menjadi peran penting dalam pengembangan turbin angin kedepannya. Salah satu pengembangan yang dapat dilakukan adalah menggunakan sistem kontrol yang dapat membaca arah angin datang dan menentukan sudut sumbu yaw agar dapat mengekstrak daya maksimum dari angin tanpa mengalami stall [6].

\section{Turbin Angin}

Turbin angin merupakan salah satu cara pemanfaatan energi angin yang berpotensi di Indonesia. Turbin angin bekerja dengan mengkonversi energi angin menjadi energi rotasi melalui blade turbin. Konsep dasar dari turbin angin adalah untuk mengkonversi energi kinetik dari angin menjadi energi mekanik yang akan digunakan untuk memutar rotor dari turbin dan menghasilkan energi listrik [14].

Turbin angin yang paling sering ditemui adalah turbin angin horisontal yang memiliki rotor dan generator pada bagian atas tiang turbin dan tersusun secara horisontal. Perputaran blade dapat terjadi dikarenakan angin yang menghempas kearah blade dengan bentuk airfoil tertentu akan menghasilkan gaya angkat pada ketiga blade yang menyebabkan pergerakan dari blade yang kemudian perputaran tersebut akan dihubungkan dengan sebuah gearbox yang digunakan untuk merubah rasio kecepatan yang dihasilkan oleh blade untuk 
digunakan pada generator agar mendapat perputaran yang maksimal. Kemudian hasil energi listrik dari generator akan disalurkan dengan kabel ke dasar tiang dimana terletak transformer step up. Turbin angin memiliki dua jenis yaitu turbin angin VAWT (Vertical Axis Wind Turbine), dan turbin angin HAWT (Horizontal Axis Wind Turbine). Turbin VAWT memiliki blade yang berotasi pada axis tegak lurus terhadap tanah, sedangkan turbin HAWT memiliki blade yang berotasi pada axis sejajar dengan tanah.

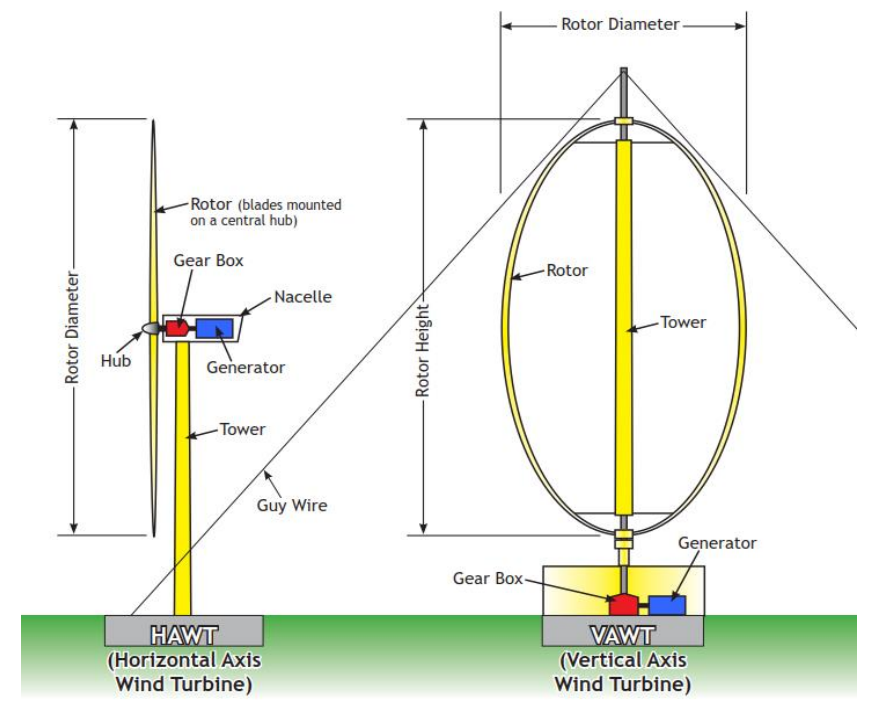

GAMBAR 1. Dua tipe turbin angin: (kiri) horizontal axis wind turbine, (kanan) vertical axis wind turbine

[15].

Pada artikel ini tipe turbin angin yang di analisa adalah turbin angin HAWT. Hal ini dikarenakan turbin angin HAWT lebih sering digunakan secara komersial sehingga akan mudah untuk diaplikasikan secara luas. Selanjutnya di teliti salah satu sistem kontrol yang digunakan untuk meningkatkan efisiensi dari turbin angin, yaitu sistem yaw. Sistem yaw merupakan sistem yang akan menggerakan bagian nacelle (sebuah tempat peletakan komponen seperti generator, gearbox, dan lain lain). Nacelle akan digerakan ketika arah angin tidak tegak lurus dengan posisi dari rotor turbin. Hal ini disebabkan ketika arah angin tidak tegak lurus dengan posisi rotor turbin, maka efisiensi yang dihasilkan tidak maksimal.

\section{METODOLOGI PENELITIAN}

Metode penelitian ini terdiri dari tiga tahap utama, yaitu perancangan, pembuatan alat, dan pengujian sistem kontrol pada miniatur. Pada tahapan perancangan miniatur dilakukan dengan mempertimbangkan skala kecil dari turbin angin yang sebenarnya. Perancangan harus disesuaikan dengan servo yang digunakan, juga memikirkan biaya total yang akan dikeluarkan. Tahapan berikutnya adalah perancangan sistem kontrol dilakukan dengan menganalisa performa dari respon alami turbin angin terhadap angin, kemudian meimplementasikan sistem kontrol PID sehingga dapat meminimalisir kesalahan. Pada bagian perancangan GUI dilakukan dengan mempertimbangkan kemudahan pengguna dalam menentukan kondisi turbin angin dan dapat melihat hasil dengan mudah. Perancangan GUI dilakukan menggunakan aplikasi LabView.

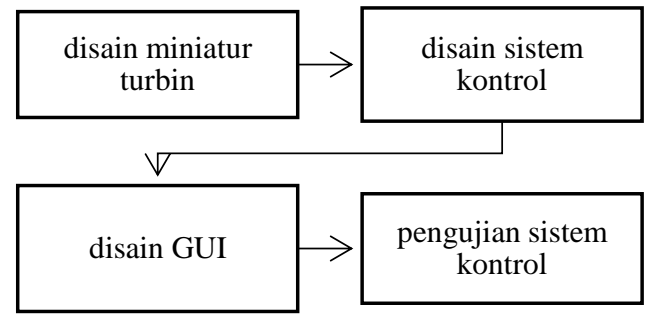

GAMBAR 2. Tahapan pembuatan sistem kontrol turbin angin yaw-direction. 
Pada gambar 3, menunjukkan gambar teknik dalam satuan centimeter, dan pergerakan yaw dilakukan pada lubang yang terdapat pada plat bagian bawah, dengan diameter lubang 9 $\mathrm{cm}$ dan akan dipenuhi dengan bearing 6011 yang berdiameter $9 \mathrm{~cm}$ juga. Tinggi plat adalah $2.2 \mathrm{~cm}$, dan dapat dilihat pada gambar dibawah, plat memiliki panjang $17 \mathrm{~cm}$ dan lebar 12 $\mathrm{cm}$, dan dengan roda gigi sebesar 1:4 (1 pada motor dan 4 pada bearing), dan material untuk gear pada penelitian ini merupakan karet. Pada bagian samping dari plat akan diletakan stepper motor yang dihubungkan dengan gear. Terakhir, seluruh sistem kontrol diimplementasikan dengan GUI dan miniatur turbin angin untuk dilihat apakah dapat terkoneksi dengan baik, dan seluruh perhitungan dapat terintegrasi dengan baik. Apabila seluruh sistem berfungsi dengan baik maka penelitian dapat dikatakan selesai.
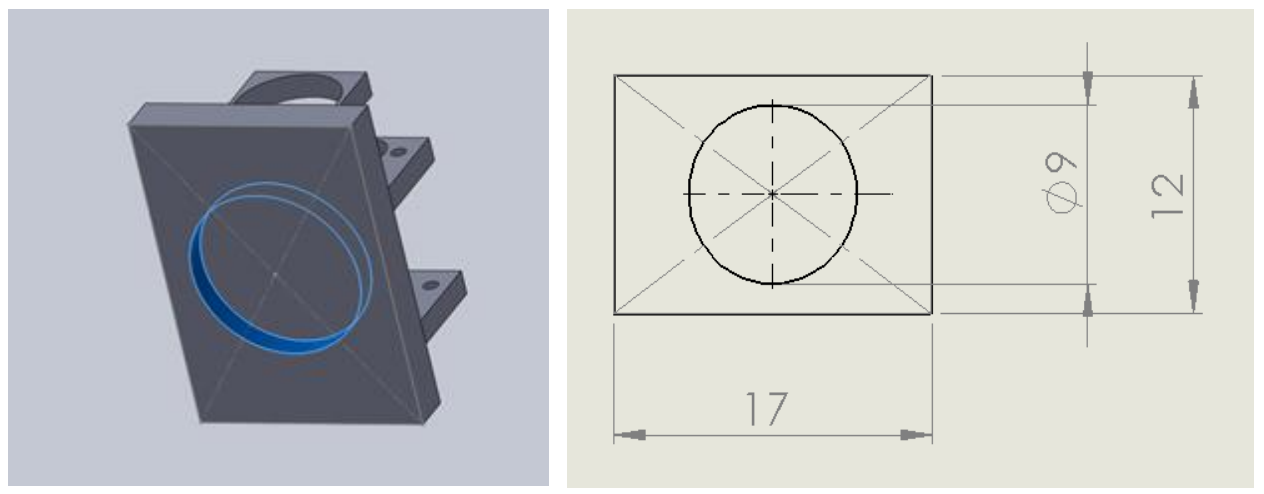

GAMBAR 3. Disain 3D assembly nacelle untuk sistem yaw dan dimensi bagian bawah plat nacelle.

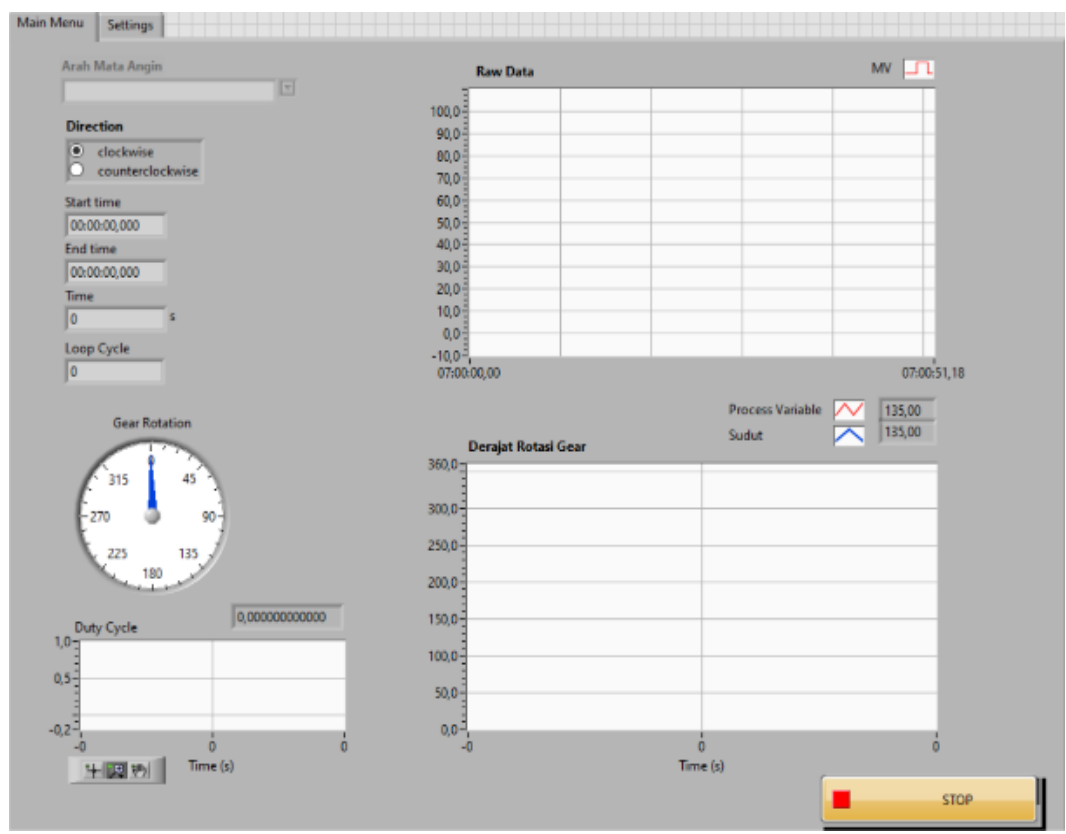

GAMBAR 4. Graphical User Iinterface (GUI) yang didisain dengan perangkat lunak LabView.

\section{HASIL DAN PEMBAHASAN}

\section{Hasil Uji Coba Konstanta $P$}

Dari gambar 5 dan 6 diperoleh melalui percobaan pengujian sistem control yang menggunakan konstanta pengujian yang sederhana yaitu dengan mengatur sistem kontrol pada konstanta P dari kontrol PID. Dapat dilihat dari hasil percobaan terdapat nilai error yang sangat besar ketika pengaturan yang sama diaplikasikan namun hanya menggunakan konstanta $\mathrm{P}$, namun memang kecepatan mencapai titik stabil jauh lebih cepat tapi pergerakan dari motor tidak sesuai dengan hasil yang diharapkan. Nilai error yang dihasilkan memiliki rata-rata sebesar $62.78 \%$. 


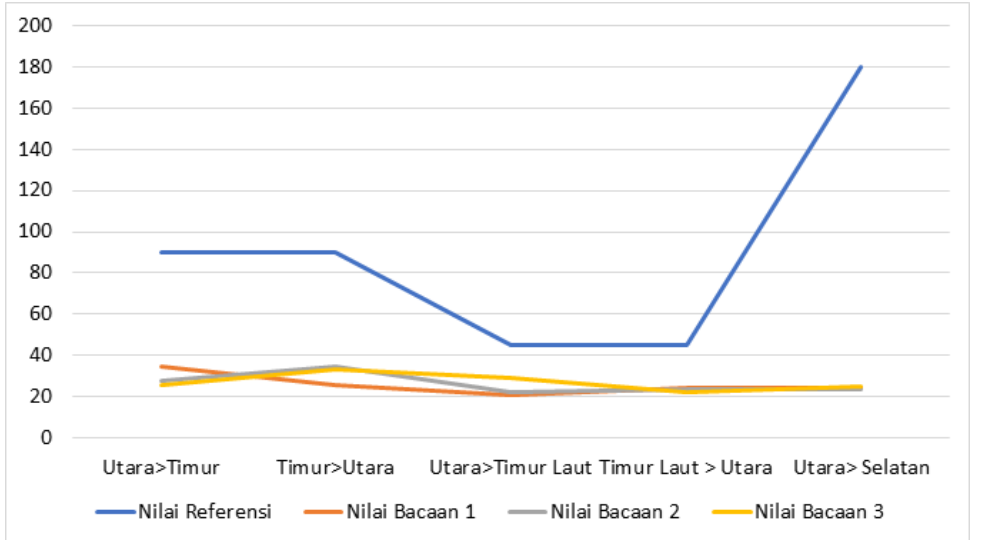

GAMBAR 5. Grafik hasil pengukuran konstanta P.

\section{Hasil Uji Coba Dengan PID}

Gambar 6 adalah penunjukan grafik pada GUI LabView yang dapat digunakan untuk membantu melihat hasil bacaan dari pergerakan motor yang dihasilkan. Data yang diperoleh menggunakan sistem kontrol dengan konstanta P, I, dan D dari kontrol PID.

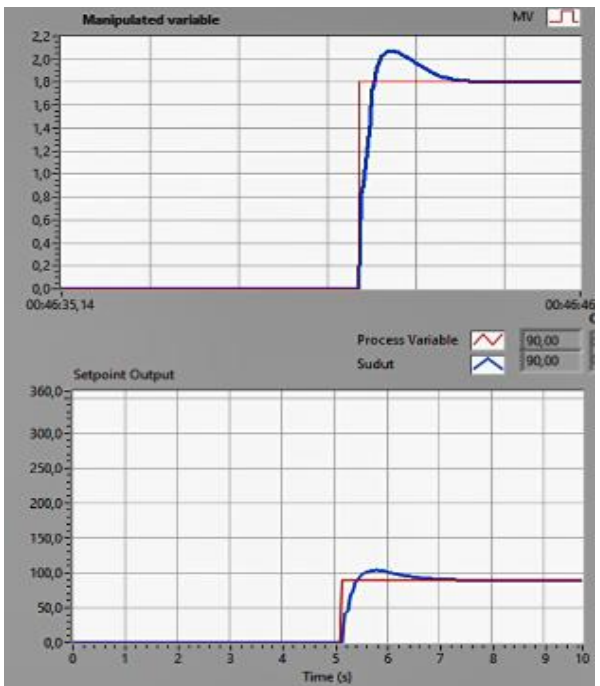

(a) utara ke timur

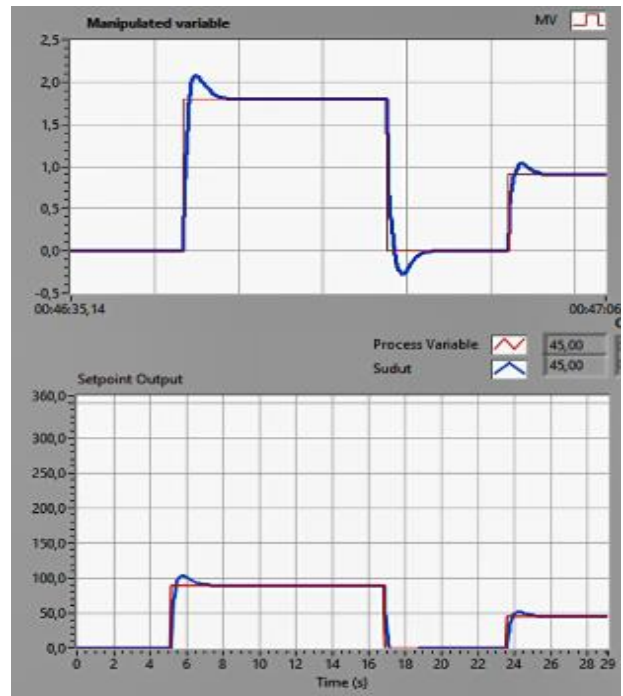

(c) utara ke timur laut

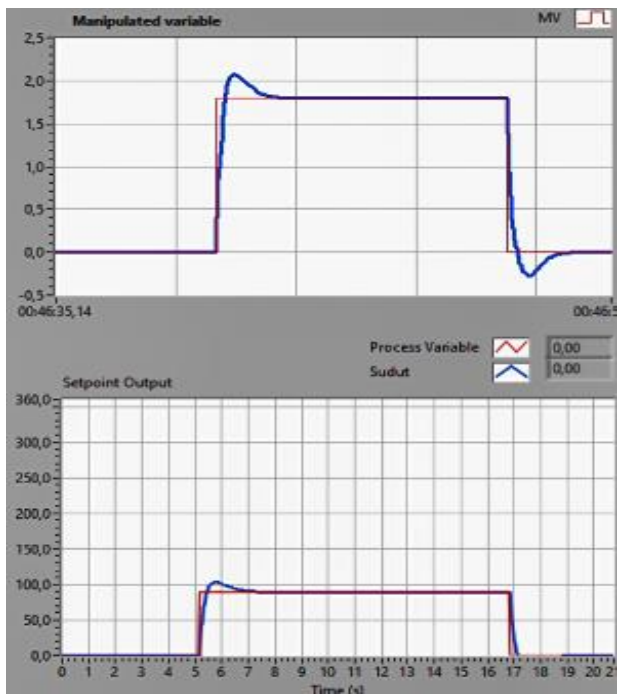

(b) timur ke utara

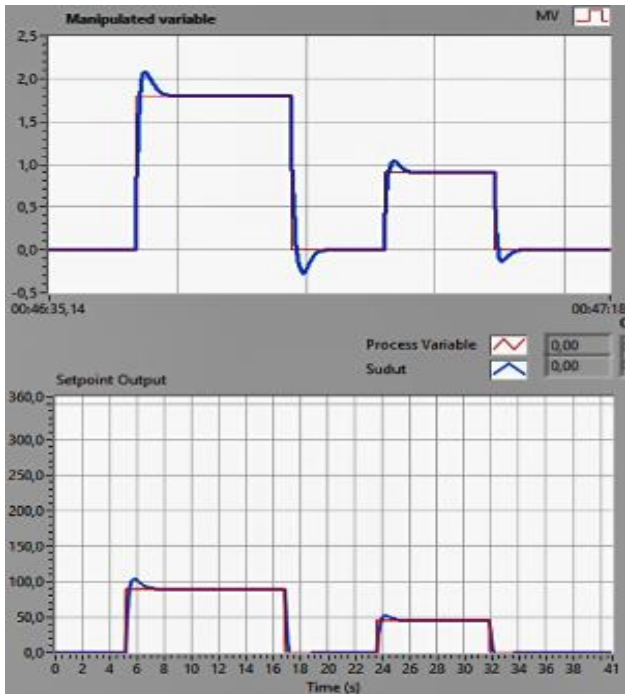

(d) timur laut ke utara

GAMBAR 6. Gambar hasil dari sistem kontrol dengan PID. Sebelah kiri adalah masukan sistem kontrol arah diawali dari utara; sebelah kanan luaran dari sistem kontrol. 
Pada gambar 7 adalah overshoot yang disebabkan oleh kontrol, namun pergerakan motor terlihat lebih halus dan cukup akurat, namun ditemukan sebuah masalah pada perpindahan input yang cukup jauh, hal ini menyebabkan error dari motor semakin membesar dan menciptakan output yang salah. Hal ini diperkirakan motor kurang dapat bergerak jauh dengan akurat karena bergantung kepada magnet statis di dalam motor dan voltase yang masuk ke motor. Nilai yang didapat untuk tiap perputaran yang dihasilkan cukup mendekati nilai referensi, pada arah angin utara ke timur, didapat nilai rata rata bacaan sebesar 93.27 derajat yang memberikan nilai error sebesar $3.6 \%$.

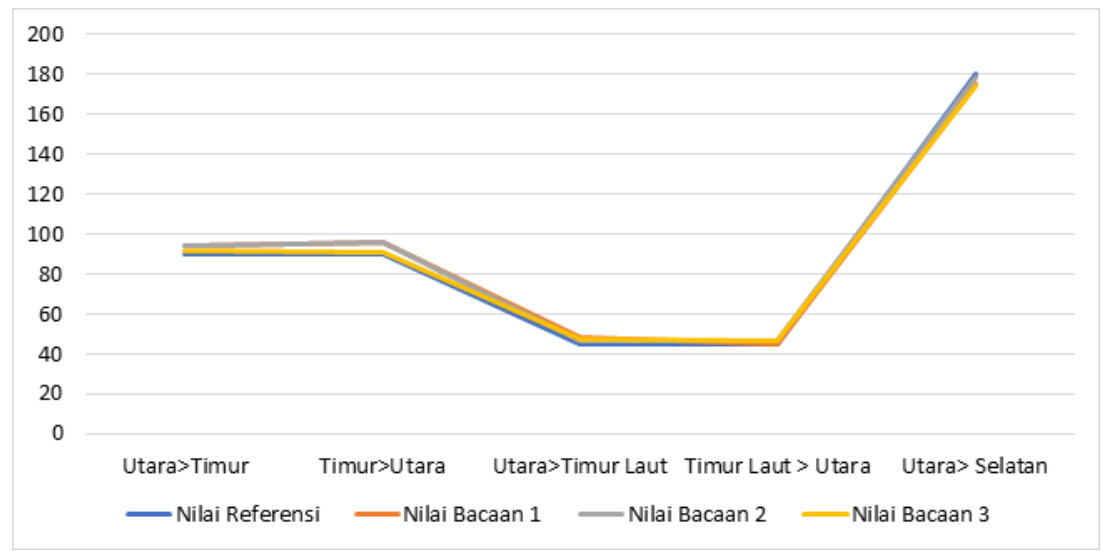

GAMBAR 7. Grafik hasil uji coba dengan konstanta PID

Kemudian pada pembacaan dari timur ke utara memiliki nilai bacaan rata rata sebesar 94.1 derajat dan memiliki nilai error sebesar $4.5 \%$, kemudian untuk dari utara ke timur laut memiliki nilai bacaan rata rata sebesar 47.26 derajat dan memiliki nilai error sebesar $5.04 \%$, selanjutnya untuk bacaan arah timur laut menuju utara memiliki bacaan rata rata sebesar 46.9 derajat dan memiliki nilai error rata rata sebesar $2.2 \%$, dan terakhir untuk bacaan dari utara ke selatan memiliki nilai rata rata sebesar 176.06 derajat dan memiliki nilai error sebesar $2.18 \%$. Terdapat sedikit error yang dihasilkan, lebih tepatnya nilai error rata rata dari keseluruhan percobaan merupakan 3.5\%, dan nilai error tersebut masih dapat diabaikan.

\section{KESIMPULAN}

Algoritma untuk sistem kontrol yaw-direction pada miniatur turbin angin dapat dilakukan menggunakan aplikasi LabView dan berhasil menampilkan user interface. Pergerakan motor dapat bergerak dengan ranah error yang masih dalam perhitungan nilai error rata rata yang dihasilkan sebesar 3.5\%. Parameter optimal yang dicari adalah kedekatan nilai bacaan dan nilai referensi dari perpindahan sudut yaw. Dengan nilai error rata rata yang masih kecil, perpindahan sudut yaw dianggap masih terjadi. Penggunaan kontrol PID pada motor meningkatkan efisiensi pergerakan motor.

\section{UCAPAN TERIMA KASIH}

Penulis mengucapkan banyak terima kasih kepada penanggungjawab laboratorium Teknik Fisika, Fakultas Teknik dan Sains, Universitas Nasional, yang telah memberikan ijin melakukan penelitian ini.

\section{DAFTAR PUSTAKA}

[1] A. Arvirianty, "RI Punya Potensi 978 MW Tenaga Angin, Ini Sebarannya," CBNC Indonesia, 2018. [Online]. Available: https://www.cnbcindonesia.com/news/20180924102847-4-34413/ri-punya-potensi- 
978-mw-tenaga-angin-ini-sebarannya.

[2] "Potensi Energi Terbarukan Indonesia," EPSILOM, 2017. [Online]. Available: https://epsilon.ft.ugm.ac.id/2017/01/16/potensi-energi-terbarukan-indonesia/.

[3] H. Shah, N. Bhattarai, S. Mathew, and C. M. Lim, "Low Reynolds Number Airfoil for Small Horizontal Axis Wind Turbine Blades," Sustain. Futur. ENERGY 2012 10th SEE FORUM, no. November, pp. 1-7, 2012.

[4] M. G. Kim and P. H. Dalhoff, "Yaw Systems for wind turbines-Overview of concepts, current challenges and design methods," J. Phys. Conf. Ser., vol. 524, no. 1, pp. 0-10, 2014.

[5] A. L. R. J. F. Manwell , J. G. McGowan, Wind energy explained : theory, design, and application, 2nd ed. John Wiley \& Sons Ltd., 2009.

[6] S. Wan, L. Cheng, and X. Sheng, "Effects of Yaw Error on Wind Turbine Running Characteristics Based on the Equivalent Wind Speed Model," Energies, vol. 8, no. 7, pp. 6286-6301, 2015.

[7] H. M. Nguyen and D. S. Naidu, "Evolution of wind turbine control systems," Encyclopedia of Life Support System, no. December. 2016.

[8] T. K. Barlas and G. A. M. van Kuik, "Review of state of the art in smart rotor control research for wind turbines," Prog. Aerosp. Sci., vol. 46, no. 1, pp. 1-27, 2010.

[9] F. Castellani, D. Astolfi, F. Natili, and F. Mari, "The Yawing Behavior of Horizontal-Axis Wind Turbines: A Numerical and Experimental Analysis," Machines, vol. 7, no. 1, 2019.

[10] R. P. Ruilope, "Modelling and Control of Stepper Motors for High Accuracy Positioning Systems Used in Radioactive Environments," PhD Thesis, Univ. Politécnica Madrid, 2014.

[11] F. Bu, W. Huang, Y. Hu, Y. Xu, K. Shi, and Q. Wang, "Study and implementation of a control algorithm for wind turbine yaw control system," in 2009 World NonGrid-Connected Wind Power and Energy Conference, 2009, pp. 1-5.

[12] M. R. Djalal, A. Imran, and H. Setiadi, "Desain Sistem Kontrol Pitch Angle Wind Turbine Horizontal Axis Menggunakan Firefly Algorithm," J. Tek. Elektro, vol. 9, no. 1, pp. 1-6, 2017.

[13] S. Theodoropoulos, D. Kandris, M. Samarakou, and G. Koulouras, "Fuzzy Regulator Design for Wind Turbine Yaw Control," TheScientificWorldJournal, vol. 2014. School of Engineering and Physical Sciences, Heriot Watt University, Edinburgh EH14 1AS, UK., p. 516394, 2014.

[14] S. P. Venkatesan, J. K. Soni, and A. Burugpalli, "Increasing efficiency of a wind turbine using a convergent nozzle in combination with a flanged diffuser," Int. J. Appl. Eng. Res., vol. 10, no. 11, pp. 10234-10240, 2015.

[15] A. K. S. Parikshit Bharpte, Sumit Saindre, Lalit Mahajan, "Electricity Generation by Maglev Windmill,” Int. Res. J. Eng. Technol., vol. 11, no. 5, pp. 1104-1109, 2018. 